\title{
$\begin{array}{lllllll}\mathbf{J} & \mathbf{o} & \mathbf{u} & \mathbf{r} & \mathbf{n} & \mathbf{a} & \mathbf{I}\end{array}$

OBITUARY

\section{In Memory of Jerry Marsden}

Published online: 6 November 2010

(C) Springer Science+Business Media, LLC 2010

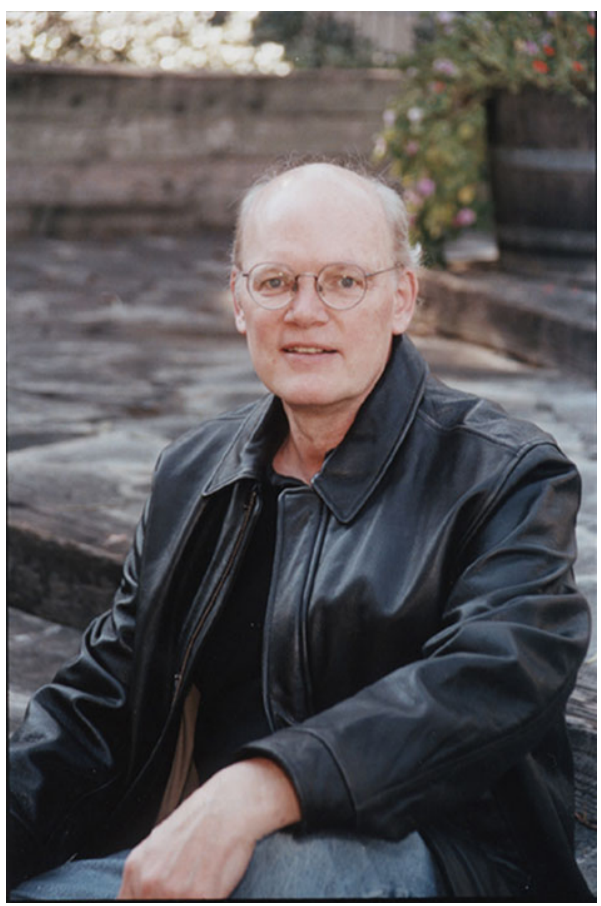

Jerry Marsden was Editor-in-Chief of the Journal at the time of his death on September 21, 2010. His broad interests in the field of nonlinear science, together with his technical skills, deep mathematical insights, calm and yet perceptive view of the world will be missed dearly by his many friends around the world.

A. Dosanjh P.J. Holmes

P.K. Newton

C. Rowley

K.R. Sreenivasan 